\title{
Teaching in higher education during COVID 19 pandemic - Empirical findings and assumptions based on results of an online-survey in a European context
}

\author{
Patricia M. Schütte ${ }^{1}$, Gert Van der Sypt ${ }^{2}$, Alexander Gabriel ${ }^{3}$, Saskia Kretschmer ${ }^{1}$ \\ ${ }^{1}$ Chair of Public Safety and Emergency Management, University of Wuppertal, Germany, \\ ${ }^{2}$ Department Science and Technology, Artesis Plantijn University of Applied Sciences and \\ Arts, Belgium, ${ }^{3}$ Institute for the Protection of Maritime Infrastructures, German Aerospace \\ Center, Germany.
}

\begin{abstract}
The COVID 19 pandemic is a worldwide phenomenon: On the one hand, it poses challenges to all social subsystems, on the other, it tests the extent to which they can cope with such situations. This is also the case in higher education. In this context, digitization, which has been driven forward in the field for years, provides approaches and instruments for adapting to such situations by converting the system as far as possible to operation in virtual space. This has been done in many places in universities and universities of applied sciences. It remains to be seen how this is perceived by those involved.

Therefore, the following article addresses the question: To what extent has the conversion of teaching and learning as a result of the restrictions on teaching caused by COVID 19 worked from the point of view of the teachers? To answer it, this paper presents empirical results of an online survey among teachers of the Cooperation Network for Risk, Safety \& Security Studies (CONRIS). The results indicate a broad use of various digital tools for teaching and communication with students, but also deficits in the area of crisis structures as well as in social regards.
\end{abstract}

Keywords: COVID 19 pandemic;teaching; digitization; higher education; online-survey; Cooperation Networkfor Risk, Safety \& Security Studies (CONRIS). 


\section{Introduction/Background}

The COVID 19 pandemic is a critical situation that is challenging for all social subsystems worldwide since the end of 2019 or the beginning of 2020. One consequence is that all systems are put to the test in terms of their ability to adapt adequately to such a situation, it tests the extent to which the systems can cope with such situations and continue with their societal functions and tasks. This is also the case in education (Bozkurt \& Sharma 2020; Daniel 2020; Mohmmed et al. 2020; Pascault et al. 2020), and here particularly higher education at universities and universities of applied sciences. Tools and approaches that the process of digitization brought years ago in the area of teaching and learning, seemed promising as relatively efficient solutions that could be implemented quickly. Converting the system as quick and as far as possible to operations in virtual space was probably an important strategy in many higher educational institutions (HEIs), not least because "Many governments have ordered institutions to cease face-to-face instruction for most of their students, requiring them to switch, almost overnight, to online teaching and virtual education." (Daniel 2020, 91). This has been done in many places in universities and universities of applied sciences, for example in Europe in March 2020 (c.f. Boer 2021). In this context a diversity of education formats or even just different descriptive adjectives for these formats in some cases - like digital, distance, online or even emergency remote teaching appeared and have been discussed (Hodges et al. 2020; Milman 2020; Mohmmed et al. 2020; Pascault et al. 2020; Schütte et al. 2020). But during a crisis situation like COVID 19, however, the higher education system is not only confronted with questions about (partly new or shifting of) teaching and learning formats. The handling of such a crisis, e.g. in the context of crisis management and communication in different crisis phases, is also a challenge. Accordingly, staff members were possibly not only teachers who were in demand in terms of their flexibility, content-related and methodological adaptability, but also as a kind of crisis manager who acted and communicated at the interface between the organization and the students. It remains to be seen how this is perceived by those involved. Therefore, the following article addresses the question:

To what extent has the conversion of teaching and learning as a result of the restrictions on teaching caused by COVID 19 worked from the point of view of the teachers?

This question was raised and further developed during a workshop of the Cooperation Network for Risk, Safety \& Security Studies (CONRIS). The CONRIS network started in 2007 as CONRIS in higher education, meaning universities and universities of applied sciences. The goal was, and is, to share knowledge across Europe concerning these study fields. Members of CONRIS meet regularly (twice a year) and organize a summer school every year. Currently, CONRIS is active in 12 countries from North to South and from Eastern to Western Europe, 18 partner universities and universities of applied sciences participate in the network (more info on www.conris.eu). 
In order to answer the question posed further above, the decision was made to conduct an online survey among the CONRIS members. This paper presents the obtained empirical results which indicate a broad use of various digital tools for teaching and communication with students, but also deficits in the area of crisis management structures as well as in social regards. After some methodological explanations (section 2), selected survey findings are presented (section 3 ) and a few theses and conclusions are formulated (section 4).

\section{Online-survey in the European network CONRIS}

\subsection{Online-survey-method - Technical and content-related aspects}

The survey was firstly developed in close cooperation between the Artesis Plantijn University of Applied Sciences and Arts in Antwerp, Belgium and the Chair of Public Safety and Emergency Management of the University of Wuppertal, Germany. The target group of the survey was primarily lecturers and academic respectively teaching staff in the institutions organized in CONRIS. In a second step, the survey developed at the two institutions mentioned above was made available to the members of the network in order to collect and incorporate the relevant feedback. Subsequently, the survey was then transferred into a digital survey tool and made available to the CONRIS network members for answering for a period of four weeks. This means that the survey ran from mid-October to mid-November 2020.

The questionnaire is divided into a general section to collect the basic statistical data of the universities, such as the country and the type of institution (university, university of applied sciences). The same section specifically collects information on teaching at HEIs prior to the pandemic. The following section attempts to capture the timing of the response as well as the actual response of the HEIs to the occurrence of the pandemic. Following this, the questionnaire aims to capture specifically how lecturers conducted their teaching in the context of the pandemic. In addition to asking how they communicated with students, subjectively perceived difficulties and challenges for the teaching staff are of particular interest here. Furthermore, the tools used as well as the availability of technical equipment in the homeoffice were surveyed. The questionnaire concludes with a block of questions about possible options for a restart of the classical (presence-based) teaching concept after the pandemic.

There were different types of questions. The majority of the questions contained an option for additional comments in order to give the lecturers and teaching staff sufficient opportunity to bring their own perspective to the foreground, which was the subject of scientific interest here. After completion of the survey, the results were transferred from the online tool to SPSS, where, after cleaning the raw data, they were subjected to a quantitative evaluation, which was supplemented with a manual qualitative evaluation. 


\subsection{Sample and analysis method}

The final sample includes ninety cases after choosing only those providing enough information for the analysis. A majority of the respondents work at a German HEIs (39\%). They are followed by employees of universities in Croatia (17\%), Belgium (12\%), the Netherlands $(12 \%)$ and Spain $(9 \%)$. Only individual cases $(<10)$ are located in Bulgaria, Finland and the UK. Most of the respondents teach full-time students (83\%). The distribution of the type of university shows that a two-thirds majority works for a university of applied scienes (UAS) $(67 \%)$. The composition of the sample, in terms of thematic orientation, was predictable due to the professional background of the CONRIS network. It shows that the Safety \& Security Sciences are particularly well represented (57\%). This group is followed by the respondents, who have a background in Social Sciences (13\%) and Engineering Sciences (11\%). There are other disciplines represented as well, but due to their differentiation in the sample they comprise less than 10 cases each.

Initially, the data was analyzed by descriptively presenting the composition of the sample. All ninety cases were examined for evaluation. Using the visualization of the response behavior, conspicuous features are then examined more closely. In individual cases, a comparison was made between the different types of universities to identify possible differences in the handling of these crises. Subsequently, the open questions were checked for content and then collectively grouped into categories to identify a trend. In the following, particular statements are depicted as examples for individual categories. These statements and the remarks from the open options for additional comments were marked as quotes and used to provide (qualitative) support for results of the survey.

The present results should be treated with caution due to the small sample size. As the group size was below 30 cases (for universities), individual group comparisons could not be performed. Afterwards, redundant answers were summarized. However, this does not affect the significance of the data. Double coding minimized the subjectivity of the data's modifications. Due to the non-representative composition of the sample, the results can only be conditionally applied to the entire field. Nevertheless, the results reveal first impressions of teaching during the pandemic.

\section{Communicating and teaching during COVID 19 pandemic - Selected empir- ical results from the CONRIS survey and assumptions}

\subsection{General results}

After restrictive measures were decided at the political level (see above), HEIs also had to react. $50 \%$ of the respondents of the CONRIS survey referred to the fact that their organiza- 
tions chose for a total lockdown, $42 \%$ chose for a teaching lockdown with practice on campus, apart from some other types of 'partial' lockdown. Most of the surveyed teaching staff answered that they followed the rules of their institution, also meaning that unclear rules had been challenging in the situation (c.f. Boer 2021; Jung et al. 2021). The following quote indicates that: "Lots of time passed until the crisis management has been worked [sic!; author's comment: working]." But elsewhere things went well: "Followed the procedures as planned, without any big problems". In a lot of cases, the conversions of presence-based teaching and learning into virtual spaces took place at the beginning or even short before the start of the semester (c.f. Boer 2021). It meant that some form of crisis communication had to take place between HEIs and students e.g. in order to inform the latter about digital procedures, new distance-teaching and -learning formats, etc. That is why the next section presents results on communication, before results on teaching are discussed in the last section of the chapter.

\subsection{Communication}

Some questions of the survey referred explicitely to the use of crisis communication and teaching plans in order to handle the first phase of the COVID 19 crisis. More than $50 \%$ of the surveyed teaching staff indicated that they 'don't know' or 'there is no plan' for teaching during crisis. Regarding the presence of a plan for crisis communication 34\% answered 'no' or 'don't know', while another $37 \%$ gave no answer which could be a hint that they also 'don't know' (s. figure 1).

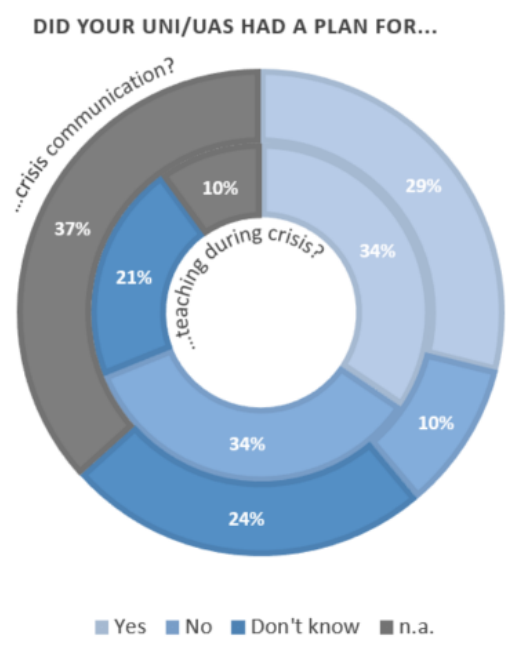

Figure 1. Crisis management plans. Source: own representation. 
The results may suggest that there is either a lack of awareness or of publicity regarding plans for teaching and communication during crises, or even in some cases also an absence of such plans. Thereby, the means the surveyed teachers used for communication varied. Most of them communicated by video communication systems e.g. Zoom, MSTeams, or simply email. Similar channels were used at the beginning of the crisis for crisis communication as well as 'normal' communication in the advanced crisis phase. Comparing the European regions from which the respondents come, vague tendencies can be derived that similar reactions concerning crisis communication can be identified everywhere as well as that similar communication tools were used. Due to the small number of cases, however, these are at most loose theses and not valid statements.

Although $21 \%$ of the questioned teaching staff felt their accessibility was worse than before the COVID pandemic, the majority of the respondents perceived themselves as accessible for students, probably due to the many means of communication available. The communication seemed to be "easier" and there was "better availability for students during the day", but particularly, social aspects of personal physical or presence meetings and "spontaneous contacts (...) were missing" (quotes from open options). The last point suggests a few aspects that are supported by answers to an open question on challenges in teaching: besides some hints to IT and technical issues, which seemed to be less relevant to the respondents, above all social and organizational challenges were named, which the following quotes show: "The communication plan changed so often (...). There was big uncertainty." or "keeping students 'on track' and motivated" or even "To keep the amount of information acceptable". They point to inconsistent communication and planning on the side of the HEIs as well as motivational and emotional considerations on the teachers' side towards their students.

\subsection{Teaching}

In terms of teaching, it becomes obvious that digital or online teaching was not new: Before COVID 19, 31\% of the respondents had at least digital support for presence-based teaching, $19 \%$ were used to blended-learning and $30 \%$ to exclusively digital teaching. Regarding teaching during the pandemic, the data shows that many types of learning methods were offered, ranging from online teaching, video-call groups up to students giving online presentations. When asked an open question about perceived lacks of/in teaching, the teachers' answers could be clustered into three categories: direct interaction/communication with students, technical equipment, feedback/exchange with colleagues. Most answers could be assigned to the category direct interaction/communication (absolute mentions $=35$ ) (s. figure 2). Twelve of the answers addressed the lack of technical equipment such as "ergonomic tools at home" or "2 big screens". One of the respondents illustrated the lack with the suffering answer "Video calling that doesn't give you a headache". 


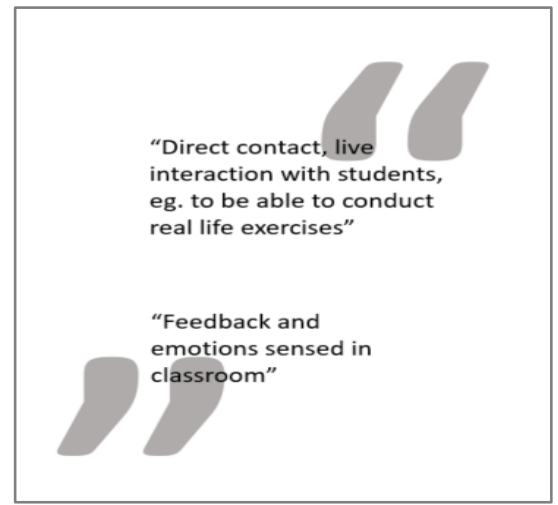

Figure 2. Perceived lacks (quotes from the category "direct interaction/communication with students"). Source: own representation.

Only six answers could be assigned to the category feedback/exchange with colleagues (c.f. Boer 2021). For example one respondent listed: "interaction, social contact, small talk, feedback, peer to peer communication".

These results also suggest that technical deficiencies are far less important to the surveyed teachers than the lack of social aspects (c.f. Jung et al. 2021). In contrast, the respondents perceived deficiencies on the part of their students primarily in technical issues like hardware, network-bandwidth, software or a quiet space to work. Social aspects and e.g. competences were mentioned less often. One explanation for this result could be that it is easier to perceive concrete technical issues (because they are recognizable immediately) than (abstract) social problems of other people. Since there were already further lockdown decisions shortly after the CONRIS-survey and HEIs in many European countries still remain in exclusively online teaching, it seems necessary to formulate a few conclusions and lessons learned for the follow-up period.

\section{Conclusions}

Lesson Learned \#1: Develop a crisis management plan and talk about it (before crisis strikes): It seems that in HEIs plans for teaching and communicating in case of a crisis do not exist everywhere, sometimes are not public or even unknown to the teaching staff. So such plans are nothing which could be taken for granted in all of the HEIs (c.f. Jung et al. 2021). But, thinking of literature and studies on (traditional) crisis management plans e.g. of civil protection organizations such plans are widely regarded as necessary to prepare and react on crises. Therefore, it seems obvious that teaching staff of HEIs who, as a type of crisis manager, take on the role of liaison persons between organizations and students should be equipped with fixed crisis management plans. Only then they are able to react appropriately 
and quickly. That is important because they represent the educating organization (e.g. university). Therefore they should be equipped with plans to provide security and reliability to students in uncertain and unpredictable situations (Bao 2020; Schütte et al. 2020).

Lesson Learned \#2: Do not underestimate influences of social aspects: Based on the mentioned results, it could be assumed that there are minor technical, but major organizational and in particular social challenges as consequences of the situation and digitization in this field - at least on the side of teaching staff HEIs. The use of diverse digital tools, channels, platforms etc. is popular with teachers to teach and communicate. It also seems that the virtual opportunities support the organizational adaptability of the organization. But, and this becomes slowly apparent after a longer duration of the crisis: Nothing replaces direct interaction between teachers and students in presence (c.f. Eringfeld 2021).

Lesson Learned \#3: Not everything that says "digital teaching" is actually digital teaching: The majority of respondents uses at least digital support tools in teaching. They seem to have been familiar with digital formats before the crisis as well. But how do these results fit to accusations about incomplete digitization of the education system (as it is the case e.g. in Germany)? How could potential discrepancies be explained? It could be seen as a hint that research is needed to take a closer look at teaching. It should be explored deeper whether it is just a temporary relabeling in terms of "online-teaching" or whether it is really a matter of concepts regarding contents, methods, didactics, etc. that are adapted to virtual possibilities (c.f. Eringfeld 2021).

\section{References}

Bao, W. (2020). Covid-19 and online teaching in higher education: A case study of Peking University. Human Behavior and Emerging Technologies, 2(2), 113-115. DOI: 10.1002/hbe2.191.

Boer, H. de (2021): COVID-19 in Dutch higher education. In Studies in Higher Education 46(1), 96-106. DOI: 10.1080/03075079.2020.1859684.

Bozkurt, A., Sharma, R.C. (2020). Emergency remote teaching in a time of global crisis due to CoronaVirus pandemic. Asian Journal of Distance Education, 15(1), i-vi. DOI: 10.5281/zenodo.3778083.

Daniel, J. (2020). Education and the COVID-19 pandemic. Prospects, 49, 91-96. DOI: 10.1007/s11125-020-09464-3.

Eringfeld, S. (2021): Higher education and its post-coronial future: utopian hopes and dystopian fears at Cambridge University during Covid-19. Studies in Higher Education 46(1), 146-157. DOI: 10.1080/03075079.2020.1859681.

Hodges, C.B., Moore, S., Lockee, B.B., Trust, T., Bond, M.A. (2020). The Difference Between Emergency Remote Teaching and Online Learning. Available online at https://medicine.hofstra.edu/pdf/faculty/facdev/facdev-article.pdf. 
Jung, J.; Horta, H., Postiglione, G.A. (2021): Living in uncertainty: the COVID-19 pandemic and higher education in Hong Kong. In Studies in Higher Education 46(1), 107-120. DOI: 10.1080/03075079.2020.1859685.

Milman, N.B. (2020). This Is Emergency Remote Teaching, Not Just Online Teaching: There's a difference. Education Week. Available online at https://www.edweek.org/leadership/opinion-this-is-emergency-remote-teaching-not-just-online-teaching/2020/03.

Mohmmed, A.O., Khidhir, B.A., Nazeer, A., Vijayan, V.J. (2020). Emergency remote teaching during Coronavirus pandemic: the current trend and future directive at Middle East College Oman. Innovative Infrastructure Solutions, 5(3). DOI: 10.1007/s41062-02000326-7.

Pascault, L., Jütte, B.J., La Noto Diega, G., Priora, G. (2020). Copyright and Remote Teaching in the Time of Coronavirus: A Study of Contractual Terms and Conditions of Selected Online Services. SSRN Electronic Journal. DOI: 10.2139/ssrn.3652183.

Schuette, P.M., Gabriel, A., Lotter, A. (2020). Impressions and Theses from Emergency Remote Teaching at The Chair of Public Safety and Emergency Management of The University of Wuppertal (during COVID 19). In Z. Krupka \& G. Vlašić (Eds.), Proceedings of 2020 Global Education, Teaching \& Learning Conference (GETL 2020) 41-52. Zagreb: Innovation Institute. 